\title{
Parent-adolescent interaction and risk of adolescent internet addiction: a population-based study in Shanghai
}

\author{
Jian Xu1', Li-xiao Shen ${ }^{1}$, Chong-huai Yan ${ }^{1 *}$, Howard Hu², Fang Yang ${ }^{3}$, Lu Wang ${ }^{4}$, Sudha Rani Kotha ${ }^{5}$, \\ Fengxiu Ouyang ${ }^{1}$, Li-na Zhang ${ }^{6}$, Xiang-peng Liao', Jun Zhang ${ }^{1}$, Jin-song Zhang ${ }^{1}$ and Xiao-ming Shen ${ }^{1 *}$
}

\begin{abstract}
Background: Family-based intervention is essential for adolescents with behavioral problems. However, limited data are available on the relationship between family-based factors and adolescent internet addiction (AIA). We aimed to examine this relationship using a representative sample of Shanghai adolescents.

Methods: In October 2007, a total of 5122 adolescents were investigated from 16 high schools via stratified-random sampling in Shanghai. Self-reported and anonymous questionnaires were used to assess parent-adolescent interaction and family environments. AIA was assessed by DRM-52 Scale, developed from Young's Internet-addiction Scale, using seven subscales to evaluate psychological symptoms of AIA.

Results: Adjusting for adolescents' ages, genders, socio-economic status, school performances and levels of the consumption expenditure, strong parental disapproval of internet-use was associated with AIA (vs. parental approval, $O R=2.20,95 \% \mathrm{Cl}: 1.24-3.91)$. Worse mother-adolescent relationships were more significantly associated with AIA $(O R=3.79,95 \% \mathrm{Cl}: 2.22-6.48)$ than worse father-adolescent relationships ( $O R=1.76,95 \%$ Cl: 1.10-2.80). Marital status of "married-but-separated" and family structure of "left-behind adolescents" were associated with symptoms of some subscales. When having high monthly allowance, resident students tended to develop AIA but commuter students did not. Family social-economic status was not associated with the development of AIA.

Conclusions: The quality of parent-adolescent relationship/communication was closely associated with the development of AIA, and maternal factors were more significantly associated with development of AIA than paternal factors. Family social-economic status moderated adolescent internet-use levels but not the development of AIA.
\end{abstract}

Keywords: Adolescents, Internet addiction, Mother-child relations, Father-child relations, China, Marital status, Family structure

\section{Background}

Rates of internet access were continuing to increase in both developing and developed countries [1-5]. With rapid rise in internet use over the past decade, and with adolescents' immature physical and psychological development, adolescent internet addiction (AIA) is increasingly becoming a serious problem and has caused great concern from the public and specialists alike [1,2,6-10].

\footnotetext{
* Correspondence: yanch@shkeylab-ceh.org; xmshen@shsmu.edu.cn 'Xinhua Hospital, MOE-Shanghai Key Laboratory of Children's Environmental Health, Department of Child and Adolescent Healthcare, Shanghai Institute for Pediatric Research, Shanghai Jiao Tong University School of Medicine, Shanghai, China

Full list of author information is available at the end of the article
}

The conceptualization or definition of internet addiction was originally based on pathological gambling and substance use, but is still debated by academics and clinicians now [11]. Nonetheless, internet addiction is generally described in the psychological literature as an individual's inability to control internet use, having the core symptoms including withdrawal reaction, preoccupation, tolerance, and significant functional impairments [11-14]. AIA reduced adolescent academic achievement, impaired psychological well-being of adolescents, and gave rise to psychosomatic symptoms and interpersonal problems in adolescents $[8,15]$. AIA may also induce structural changes in the brain regions including anterior 
cingulated cortex, orbitofrontal cortex and dorsolateral prefrontal cortex, or executive dysfunction such as elevated impulsivity and impaired cognitive control $[13,16]$.

Identification of family characteristics of adolescent internet addicts is helpful for family-based intervention, considered the essential part of cognitive behavioral treatment and psychosocial support for adolescent internet addicts [11]. However, limited data are available on the relationship between AIA and family.

Poor family function was found to be one of the most important risk factors for addictive substance use and other severely abnormal adolescent behaviors [15,17-21]. Some studies have noted that family may play a role in the development of AIA [2,22], but many limitations existed in those studies. Firstly, maternal role and paternal role in the development of AIA were not separately discussed in detail before, and details on family economic levels were not questioned. Secondly, in previous studies, the independent risk factors for AIA from family environments were not explored after controlling for adolescent school performances and levels of the consumption expenditure. Finally, most of the previous studies were conducted in small and non-representative study populations, and the corresponding results may be biased due to nonprobability sampling. Therefore, there is a need for more representative surveys $[4,22,23]$.

The objective of this study was to identify the relationship between AIA and patterns of parent-adolescent interaction using a representative sample of Shanghai adolescents.

\section{Methods}

\section{Study design and participants}

The sample was recruited from junior and senior high schools in Shanghai from October to November 2007. The survey was an anonymous, self-administered and paper-and-pencil questionnaire, conducted in classroom settings.

Stratified and cluster random sampling was performed to ensure that participants were representative of the overall adolescent population in Shanghai. Sampling method was described in detail before [5]. We randomly selected 6 administrative districts out of 19 administrative districts in Shanghai depending on their geographical features, socioeconomic characteristics, and population density. Within the 6 districts, in urban or suburban area, we randomly selected 2 junior high schools and 6 senior high schools ( 2 ordinary, 2 key, and 2 vocational). All the students in $7^{\text {th }}-12^{\text {th }}$ grades in each school were enrolled. Therefore, in total, 16 high schools and 5135 adolescents were recruited. Thirteen subjects were excluded based on missing data on more than 3 variables in general information questionnaire or due to missing data in DRM-52 Scale. This resulted in a total sample of 5122 adolescents (response rate: 99.8\%).
School approval and parental informed consent (written) were obtained at the study's initiation. The study received approval from the medical ethical committee of Xinhua Hospital affiliated to Shanghai Jiao Tong University School of Medicine.

\section{Variables}

The questionnaire contained 3 parts: 1) individual adolescent information included age, gender, grade, district and the type of school, 2) family factors, self-assessed levels of academic achievement and levels of monthly consumption expenditure that may potentially affect internet use, 3) adolescent behaviors of internet usage. Familial background variables included parental education levels, occupations, marital status, family structure, residence rented or owned, having cars/computers/internet access at home or not, adolescent having private bedrooms or not, only child or not, residential or commuter students, adolescents' monthly allowance levels. Quality of the parent-adolescent relationship was evaluated with data from answers to the following questions: What is your perception of the quality of your mother-father relationship? Of your relationship with your mother? Of your relationship with your father? What is your perception of parental attitude toward your internet use?

\section{Measures}

AIA was assessed by DRM-52 Scale, developed from Young's Internet-Addiction Scale and adapted for use in Shanghai $[5,12,24]$. The scale included all contents of Young's scale, used both direct and indirect questions to collect data, and used seven subscales to evaluate psychological symptoms of AIA. A detailed description of the contents of seven subscales and psychometric properties of the scale was described before [5,24].

The total score on DRM-52 Scale ranged from 0 to 260. A score of zero meant that an adolescent never used the internet, a score over 163 was defined as internet addiction, and higher scores indicated increasing severity of internet addiction [5,24].

\section{Statistical analysis}

For univariate analyses, a one-way analysis of variance (ANOVA) was used to analyze the differences of total scores of DRM-52 Scale and Chi-square was used to compare the prevalence rates of AIA or internet-use among different levels of the same family background variable. For multivariable regression, binary logistic regression and multiple linear regression analyses (stepwise model) were both adopted to evaluate the strength of association between family factors and AIA, and linear regression was also used to evaluate the association between family factors and symptoms of seven subscales. In the first stage, Base Model 1 included all family background variables mentioned above 
(in "Variables"); Base Model 2 included adolescent personal variables such as adolescents' genders, grades, types of schools, levels of academic achievement and levels of monthly consumption expenditure [5]. To control for potential confounding, we used another two models to evaluate the effects of family on the development of AIA. Model 1 adjusted for all the personal variables included in Base model 2 which were shown to be independent risk factors for AIA [5]. Because possible relationship between family structure, marital status, and AIA were mentioned in previous studies [2,18,21,22], Model 2 was performed to force two additional variables including family structure and marital status into the model. Data stratification by adolescent boarding status and monthly allowance was performed. The statistical significance was set at $p<0.05$ (two tailed)

\section{Results}

Of the 5122 participants, the mean age of respondents was 15.9 years with a range from 11.3 to 20.4 years, and the boy/girl ratio was close to $1: 1$ (2542 boys, 49.6\%; 2580 girls, 50.4\%). As shown in Tables 1 and 2, the sample was from diverse socioeconomic backgrounds.

\section{Bivariate associations between family background variables and adolescent internet-use/internet-addiction} Adolescent internet-use levels were found to be associated with factors relating to family's social-economic status (SES). Adolescents from high SES families had higher internet-use levels than adolescents from low SES families (Table 1).

Of parent-adolescent interaction patterns, compared with adolescents whose parents approved of their internet use, adolescents who perceived strong parental disapproval had lower internet-use levels but with higher total scores and a higher prevalence of AIA. Adolescents with worse relationships with the mother or with the father had higher total scores and a higher prevalence of AIA. Of marital status, adolescents from married-butseparated families had the highest total scores and the highest prevalence of AIA (Table 2).

\section{Adjusted associations between family background variables and adolescent internet-use/internet-addiction} After controlling for confounding influences, both multivariate linear regression and logistic regression analyses showed that adolescents whose parents strongly disapproved of their internet-use had higher risks of AIA than adolescents whose parents approved (odds ratio (OR): 2.20, 95\% confidential interval (CI): 1.24-3.91, Table 3), and were significantly associated with symptoms of 6 subscales (however, not significantly associated with the TimeConsuming symptom) (Table 4). When compared to adolescents who had good mother relationships, adolescents with bad mother relationships were more likely to develop AIA (OR 3.79, 95\% CI: 2.22-6.48, Table 3), and had corresponding symptoms in Socialization, Planning, NegativeLife-Consequences and Tolerance subscales (Table 4). Bad father-adolescent relationship was associated with AIA (OR 1.76, 95\% CI: 1.10-2.80) and with the symptom of Withdrawal subscale (Tables 3 and 4).

In Model 2, we found significant association between marital status of married-but-separated and AIA (OR: 2.06, 95\% CI: 1.05-4.06, Table 3), and between marital status of married-but-separated and significant symptoms in Lackof-Control and Withdrawal subscales (Table 4), and association between family structure of three-generation families and fewer symptoms in Negative-Life-Consequence and Tolerance subscales, as well as significant association between family structure of left-behind adolescents and Time-Consuming subscale (Table 4). Results indicated a marginal association between the total scores of DRM-52 Scale and variables of family structure and marital status, suggesting that these two variables were potential but not strong risk factors for AIA.

For resident students, high monthly allowance was associated with higher risk of AIA (> $600 \mathrm{RMB} /$ month vs < $100 \mathrm{RMB} /$ month, OR: 3.60, 95\% CI: 1.27-10.20). However, for commuter students, adolescents with high monthly allowance were not significantly associated with AIA (Table 3).

No factors related to family SES entered any final regression models.

\section{Discussion}

This study demonstrated that parent-adolescent interactions played an important role in the development of AIA. However, familial SES had no significant impact on the development of AIA.

\section{Parent-adolescent interaction compared to family SES in the development of AIA}

Our study showed that strong parental disapproval of adolescent internet use was significantly associated with the development of AIA. This may be explained by the poor quality of parent-adolescent communication such that adolescents were unwilling to take advice from their parents. Previous studies [25] found that adolescents' perceptions of parental disapproval of their engaging in sex might be associated with increased risk for adolescent sexual behavior, and adolescent perceptions of parental attitudes tended to be more predictive of risky sexual behavior than actual parental attitudes. This trend was verified in our study that showed the importance of improving parent-adolescent communication.

Few studies discussed the role of family economic status in AIA. The result of one small study was consistent with ours in that family SES had no significant effects on 
Table 1 Family characteristics of the study population of 5122 adolescents in Shanghai

\begin{tabular}{|c|c|c|c|c|}
\hline Variables & $\mathrm{N}(\%)$ & Prevalence of Internet use (\%) ${ }^{a}$ & Total scores $^{\mathbf{b}}$ & Prevalence of AIA $(\%)^{c, d}$ \\
\hline Paternal education (missing 23) & & $p<0.001$ & $p<0.001$ & $p=0.01$ \\
\hline Illiteracy and elementary & $101(2.0 \%)$ & $84.2 \%(85 / 101)$ & $112.3 \pm 53.7$ & $9.9 \%(10 / 101)$ \\
\hline Junior high school & $1115(21.8 \%)$ & $92.8 \%(1035 / 1115)$ & $116.9 \pm 43.3$ & $8.7 \%(97 / 1115)$ \\
\hline Senior high school & $2362(46.1 \%)$ & $94.9 \%(2242 / 2362)$ & $122.8 \pm 39.1$ & $10.0 \%(235 / 2362)$ \\
\hline University-level and beyond & $1521(29.7 \%)$ & $93.6 \%(1424 / 1521)$ & $117.4 \pm 40.5$ & $6.8 \%(104 / 1521)$ \\
\hline Maternal education (missing 26) & & $p=0.002$ & $p<0.001$ & $p=0.001$ \\
\hline Illiteracy and elementary & $147(2.9 \%)$ & $91.2 \%(134 / 147)$ & $110.8 \pm 44.0$ & $4.1 \%(6 / 147)$ \\
\hline Junior high school & $1215(23.7 \%)$ & $92.2 \%(1120 / 1215)$ & $116.4 \pm 43.6$ & $8.7 \%(106 / 1215)$ \\
\hline Senior high school & $2327(45.4 \%)$ & $94.8 \%(2206 / 2327)$ & $123.2 \pm 39.5$ & $10.3 \%(239 / 2327)$ \\
\hline University-level and beyond & 1407 (27.5\%) & $94.0 \%(1323 / 1407)$ & $117.6 \pm 40.0$ & $6.9 \%(97 / 1407)$ \\
\hline Family structure (missing 0 ) & & $p=0.22$ & $p=0.01$ & $p=0.01$ \\
\hline Nuclear family & $3380(66.0 \%)$ & $93.5 \%(3158 / 3380)$ & $118.9 \pm 41.2$ & $8.5 \%(288 / 3380)$ \\
\hline Three-generation family & 1069 (20.9\%) & $95.0 \%(1016 / 1069)$ & $118.9 \pm 38.9$ & $7.5 \%(80 / 1069)$ \\
\hline Single parent family & $357(7.0 \%)$ & $93.6 \%(334 / 357)$ & $124.3 \pm 44.0$ & $13.2 \%(47 / 357)$ \\
\hline Left-behind adolescents & $181(3.5 \%)$ & $93.9 \%(170 / 181)$ & $124.7 \pm 43.5$ & $12.2 \%(22 / 181)$ \\
\hline Weekend parents & $135(2.6 \%)$ & $96.3 \%(130 / 135)$ & $126.8 \pm 35.1$ & $9.6 \%(13 / 135)$ \\
\hline Parental marriage (missing 4) & & $p=0.23$ & $p=0.003$ & $p=0.004$ \\
\hline Married \& together & 4477 (87.4\%) & $93.9 \%(4202 / 4477)$ & $119.0 \pm 40.5$ & $8.3 \%(370 / 4477)$ \\
\hline Married-but-separated & $81(1.6 \%)$ & $93.8 \%(76 / 81)$ & $132.5 \pm 44.2$ & $17.3 \%(14 / 81)$ \\
\hline Divorced & $360(7.0 \%)$ & $93.6 \%(337 / 360)$ & $124.2 \pm 43.5$ & $12.2 \%(44 / 360)$ \\
\hline Widowed & $86(1.7 \%)$ & $90.7 \%(78 / 86)$ & $117.5 \pm 47.1$ & $10.5 \%(9 / 86)$ \\
\hline Remarried & $114(2.2 \%)$ & $97.4 \%(111 / 114)$ & $125.6 \pm 35.9$ & $11.4 \%(13 / 114)$ \\
\hline Commuter students or not (missing 13) & & $p=0.03$ & $p=0.002$ & $p=0.67$ \\
\hline Resident students & $451(8.8 \%)$ & $96.0 \%(433 / 451)$ & $125.2 \pm 35.6$ & $9.5 \%(43 / 451)$ \\
\hline Commuter students & $4668(91.2 \%)$ & $93.7 \%(4372 / 4668)$ & $119.2 \pm 41.3$ & $8.7 \%(407 / 4668)$ \\
\hline Only child (missing 12) & & $p=0.34$ & $p=0.21$ & $p=0.56$ \\
\hline Yes & $4658(90.9 \%)$ & $94.0 \%(4377 / 4658)$ & $119.9 \pm 40.8$ & $8.9 \%(413 / 4658)$ \\
\hline No & $452(8.8 \%)$ & $92.9 \%(420 / 452)$ & $117.4 \pm 42.0$ & $8.0 \%(36 / 452)$ \\
\hline Family housing (missing 18) & & $p<0.001$ & $p=0.01$ & $p=0.27$ \\
\hline Own & $4724(92.2 \%)$ & $94.3 \%(4455 / 4724)$ & $120.1 \pm 40.3$ & $9.0 \%(423 / 4724)$ \\
\hline Rent & $380(7.4 \%)$ & $89.0 \%(338 / 380)$ & $114.4 \pm 46.9$ & $6.8 \%(26 / 380)$ \\
\hline Having computers at home (missing 3 ) & & $p<0.001$ & $p<0.001$ & $p<0.001$ \\
\hline Yes & $4359(85.1 \%)$ & $96.5 \%(4208 / 4359)$ & $123.9 \pm 36.4$ & $9.7 \%(422 / 4359)$ \\
\hline No & $760(14.8 \%)$ & $78.6 \%(597 / 760)$ & $95.2 \pm 54.4$ & $3.7 \%(28 / 760)$ \\
\hline Having private bedroom (missing 9) & & $p<0.001$ & $p=0.02$ & $p=0.32$ \\
\hline Yes & 4169 (81.4\%) & $94.5 \%(3940 / 4169)$ & $120.3 \pm 39.7$ & $8.6 \%(360 / 4169)$ \\
\hline No & 944 (18.4\%) & $91.1 \%(860 / 944)$ & $116.8 \pm 45.6$ & $9.3 \%(88 / 944)$ \\
\hline
\end{tabular}

a Prevalence of Internet use: the ratio of the number of adolescents using internet to the number of the whole adolescent sample in that group. Chi-square was used to compare the prevalences of internet-use among different levels of the same family background variable.

${ }^{b}$ Total scores: total scores of DRM-52 Scale. ANOVA was used to analyze the differences of total scores of DRM-52 Scale among different levels of the same family background variable.

${ }^{\mathrm{C}} \mathrm{AI} \mathrm{A}=$ adolescent internet addiction.

${ }^{\mathrm{d}}$ Prevalence of AIA: the ratio of the number of internet-addicted adolescents to the number of the whole adolescent sample in that group. Chi-square was used to compare the prevalences of AIA among different levels of the same family background variable. 
Table 2 Parent-adolescent interaction and AIA in 5122 Shanghai adolescents ${ }^{a}$

\begin{tabular}{|c|c|c|c|c|}
\hline Variables & $\mathrm{N}(\%)$ & Prevalence of internet use $(\%)^{\mathbf{b}}$ & Total scores $^{c}$ & Prevalence of AIA (\%) $^{d}$ \\
\hline Father-mother relationship (missing 27) & & $p=0.75$ & $p<0.001$ & $p<0.001$ \\
\hline Very good & $3640(71.1 \%)$ & $93.7 \%(3410 / 3640)$ & $116.5 \pm 40.4$ & $6.7 \%(243 / 3640)$ \\
\hline Relatively good & $794(15.5 \%)$ & $94.1 \%(747 / 794)$ & $127.8 \pm 41.0$ & $14.1 \%(112 / 794)$ \\
\hline General & $379(7.4 \%)$ & $94.2 \%(357 / 379)$ & $127.6 \pm 42.4$ & $15.6 \%(59 / 379)$ \\
\hline Relatively \& very bad & $282(5.5 \%)$ & $95.0 \%(268 / 282)$ & $127.3 \pm 41.0$ & $12.4 \%(35 / 282)$ \\
\hline Father-adolescent relationship (missing 19) & & $p=0.87$ & $p<0.001$ & $p<0.001$ \\
\hline Very good & $2691(52.5 \%)$ & $93.7 \%(2521 / 2691)$ & $114.5 \pm 40.3$ & $6.1 \%(163 / 2691)$ \\
\hline Relatively good & $1332(26.0 \%)$ & $93.9 \%(1251 / 1332)$ & $122.7 \pm 39.9$ & $10.2 \%(136 / 1332)$ \\
\hline General & $888(17.3 \%)$ & $94.4 \%(838 / 888)$ & $128.2 \pm 40.8$ & $12.6 \%(112 / 888)$ \\
\hline Relatively \& very bad & $192(3.8 \%)$ & $93.2 \%(179 / 192)$ & $130.0 \pm 45.1$ & $18.2 \%(35 / 192)$ \\
\hline Mother-adolescent relationship (missing 17) & & $p=0.71$ & $p<0.001$ & $p<0.001$ \\
\hline Very good & $3137(61.3 \%)$ & $94.1 \%(2953 / 3137)$ & $115.4 \pm 39.7$ & $6.28 \%(197 / 3137)$ \\
\hline Relatively good & $1353(26.4 \%)$ & $93.4 \%(1263 / 1353)$ & $125.0 \pm 41.7$ & $11.5 \%(155 / 1353)$ \\
\hline General & $522(10.2 \%)$ & $93.1 \%(486 / 522)$ & $127.8 \pm 42.2$ & $12.6 \%(66 / 522)$ \\
\hline Relatively \& very bad & $93(1.8 \%)$ & $95.7 \%(89 / 93)$ & $137.3 \pm 44.1$ & $31.12 \%(29 / 93)$ \\
\hline Parental attitude toward internet use (missing 18) & & $p<0.001$ & $p=0.004$ & $p<0.001$ \\
\hline Agree & $441(8.6 \%)$ & $95.5 \%(421 / 441)$ & $119.7 \pm 38.4$ & $7.0 \%(31 / 441)$ \\
\hline Relatively agree & $1688(33.0 \%)$ & $96.9 \%(1635 / 1688)$ & $119.4 \pm 33.6$ & $6.3 \%(107 / 1688)$ \\
\hline General & $1437(28.1 \%)$ & $93.7 \%(1346 / 1437)$ & $120.2 \pm 41.2$ & $8.6 \%(124 / 1437)$ \\
\hline Relatively disagree & $1312(25.6 \%)$ & $92.2 \%(1209 / 1312)$ & $121.7 \pm 44.7$ & $11.5 \%(151 / 1312)$ \\
\hline Strongly disagree & $226(4.4 \%)$ & $82.7 \%(187 / 226)$ & $110.3 \pm 59.2$ & $15.5 \%(35 / 226)$ \\
\hline Adolescent monthly allowance (missing 14) & & $p<0.001$ & $p<0.001$ & $p<0.001$ \\
\hline$<100 \mathrm{RMB}$ & $2776(54.2 \%)$ & $92.2 \%(2561 / 2776)$ & $112.0 \pm 42.3$ & $6.5 \%(179 / 2776)$ \\
\hline $100 \sim 299$ RMB & $1572(30.7 \%)$ & $95.5 \%(1503 / 1572)$ & $127.0 \pm 37.6$ & $10.6 \%(167 / 1572)$ \\
\hline $300 \sim 599 \mathrm{RMB}$ & $541(10.6 \%)$ & $97.8 \%(529 / 541)$ & $132.0 \pm 33.3$ & $12.9 \%(70 / 541)$ \\
\hline$>600 \mathrm{RMB}$ & $219(4.3 \%)$ & $93.6 \%(205 / 219)$ & $132.8 \pm 42.6$ & $15.1 \%(33 / 219)$ \\
\hline
\end{tabular}

${ }^{\mathrm{a}} \mathrm{AIA}=$ adolescent internet addiction.

bPrevalence of Internet use: the ratio of the number of adolescents using internet to the number of the whole adolescent sample in that group. Chi-square was used to compare the prevalences of internet-use among different levels of the same family background variable.

'Total scores: total scores of DRM-52 Scale. ANOVA was used to analyze the differences of total scores of DRM-52 Scale among different levels of the same family background variable.

dPrevalence of AIA: the ratio of the number of internet-addicted adolescents to the number of the whole adolescent sample in that group. Chi-square was used to compare the prevalences of AIA among different levels of the same family background variable.

AIA [22]. As for the role of monetary allowance in adolescent behaviors, one previous paper reported significant association between high monthly allowance and smoking in young urban Malaysian women [26]. In this study, high monthly allowance was a risk factor for AIA in resident students, but not a risk factor for AIA in commuter students. Due to relative freedom from parental supervision, high monthly allowance may provide opportunities to resident students to frequently use internet. "Peer effects" (peer influences on drinking, smoking, and frequent internet usage) may also have significant impacts on development of AIA in resident students [27]. However, for commuter students, their parents usually had more opportunities to supervise their spending of money, in general, their daily living expenses had been paid by their parents directly. Therefore, higher monthly allowance might not be related to more monthly spending in commuter students, rather, it reflect the common parental confidence in those adolescents. This result also suggested the importance of parental supervision and parent-adolescent harmonious interaction in prevention of AIA.

\section{The maternal and paternal roles in guiding adolescent} internet use

Maternal factors were found to play a central role in guiding adolescents in appropriate internet use. A previous study contrasting 72 mother-child dyads in the Netherlands and another study investigating 635 Arab Muslim immigrant mother-adolescent pairs both found that mother-adolescent relationship affected adolescent 
Table 3 Logistic regression analysis results for the association between parent-adolescent interaction and AIA development ${ }^{\mathrm{a}, \mathrm{b}}$

\section{Potential risk factors}

Parental attitude toward adolescent internet use

Agree

Relatively agree

General

Relatively disagree

Strongly disagree

Mother-adolescent relationship

Very good

Relatively good

General

Very \& relatively bad

Father-adolescent relationship

Very good

Relatively good

General

Very \& relatively bad

Parental marriage

Married-and-together

Married-but-separated

Divorced

Widowed

Remarried

Family structure

Nuclear family

Three-generation family

Single-parent family

Left-behind adolescents

Weekend parents

Monthly allowance levels

Among resident students

$<100 \mathrm{RMB} /$ month

$100 \sim 299$ RMB/month

\section{Odds ratio $(95 \% \mathrm{Cl})$}

Base Model $1^{\mathrm{C}}$ (Un-adjusted)

Model $2^{\mathrm{d}}$ (Adjusted)

5104

441

1688

1437

1312

226

5105

3137

1353

522

93

5103

269

1332

888

192

5118

4477

81

360

86

114

5122

3380

1069

357

181

135

5108

451

105

154
1.0 (Reference)

0.90(0.59-1.36)

1.25(0.83-1.88)

$1.72(1.15-2.57)^{* * e}$

$2.42(1.45-4.05)$ **e

1.0 (Reference)

$1.93(1.55-2.41)^{* * *}$

$2.16(1.61-2.90)^{* * *}$

$6.76(4.26-10.73)^{* * *}$

1.0 (Reference)

$1.76(1.39-2.24)^{* * *}$

2.24(1.74-2.89)***

$3.46(2.32-5.15)^{* * *}$

1.0 (Reference)

2.32(1.29-4.17)**

$1.55(1.11-2.16)^{*}$

$1.30(0.65-2.61)$

$1.43(0.79-2.57)$

1.0 (Reference)

0.87(0.67-1.12)

1.63(1.17-2.26)*

$1.49(0.94-2.37)$

$1.14(0.64-2.05)$

1.0 (Reference)

0.66(0.24-1.83)
1.0 (Reference)

1.05(0.67-1.64)

1.08(0.69-1.69)

1.54(0.98-2.40)

2.20(1.24-3.91)**e

1.0 (Reference)

$1.25(0.95-1.66)$

$1.20(0.83-1.73)$

$3.79(2.22-6.48)^{* * *}$

1.0 (Reference)

1.39(0.99-1.93)

$1.76(1.10-2.80)^{*}$

1.0 (Reference)

2.06(1.05-4.06)*

$1.14(0.74-1.75)$

$1.52(0.66-3.47)$

$1.13(0.61-2.10)$

1.0 (Reference)

0.84(0.64-1.11)

1.19(0.79-1.79)

$1.26(0.76-2.08)$

$0.94(0.50-1.76)$

1.0 (Reference)

0.59(0.20-1.76)
1.32(0.98-1.76) 
Table 3 Logistic regression analysis results for the association between parent-adolescent interaction and AIA development ${ }^{\mathrm{a}, \mathrm{b}}$ (Continued)

\begin{tabular}{|c|c|c|c|}
\hline $300 \sim 599$ RMB/month & 131 & $1.34(0.53-3.36)^{*}$ & $1.15(0.43-3.13)$ \\
\hline$>600$ RMB/month & 61 & $3.61(1.42-9.21)^{* *}$ & $3.60(1.27-10.20)^{*}$ \\
\hline Among commuter students & 4657 & & \\
\hline$<100 \mathrm{RMB} /$ month & 2671 & 1.0 (Reference) & 1.0 (Reference) \\
\hline $100 \sim 299$ RMB/month & 1418 & $1.85(1.47-2.32)^{* * *}$ & $1.64(1.28-2.11)^{* * *}$ \\
\hline $300 \sim 599$ RMB/month & 410 & $2.36(1.72-3.25)^{* * *}$ & $1.75(1.22-2.50)^{* *}$ \\
\hline$>600 \mathrm{RMB} /$ month & 158 & $2.00(1.21-3.31)^{* *}$ & $1.32(0.76-2.31)$ \\
\hline
\end{tabular}

'The logistic regressions were fitted to model the possibility of adolescent having AIA. We set " 0 " for adolescents with total scores of DRM 52 scale $<163$ and " 1 " for adolescents with total scores $\geq 163$.

In Base Model 1, only family background variables were included.

In model 2, family background variables (same variables in Base Model 1) and other related variables including grades, types of schools, monthly consumption expenditure levels, academic achievement levels and family social
$\mathrm{d}^{\prime}$ n

economic status were adjusted. Two variables including family structure and marital status were forced in this model.

e***indicated $p<0.001$ **indicated $p<0.01$, *indicated $p<0.05$. 
Table 4 Linear regression results for the associations between family factors and development of AIA/AIA symptoms ${ }^{\mathrm{a}, \mathrm{b}}$

\begin{tabular}{|c|c|c|c|c|c|c|c|c|}
\hline \multirow[t]{2}{*}{ Potential risk factors } & \multirow[t]{2}{*}{ Total score ${ }^{c}$} & \multicolumn{7}{|c|}{ Seven subscale scores ${ }^{c}$} \\
\hline & & Lack of Control & Socialization & Planning & Negative-Life-Consequences & Time-Consuming & Tolerance & Withdrawal \\
\hline \multicolumn{9}{|c|}{ Parental attitude toward adolescent internet use } \\
\hline Agree & Reference & Reference & Reference & Reference & Reference & Reference & Reference & Reference \\
\hline Relatively agree & $1.0(1.5)^{\mathrm{d}}$ & $0.5(0.2)^{d}$ & $0.6(0.3)^{d}$ & $0.2(0.2)^{d}$ & $0.1(0.3)^{d}$ & $-0.2(0.2)^{d}$ & $-0.0(0.2)^{d}$ & $-0.2(0.5)^{d}$ \\
\hline General & $0.7(1.5)$ & $0.4(0.2)$ & $0.6(0.3)$ & $0.4(0.2)$ & $0.4(0.3)$ & $-0.2(0.2)$ & $-0.3(0.2)$ & $-0.6(0.6)$ \\
\hline Relatively disagree & $5.8(1.6)^{* * * e}$ & $1.1(0.2)^{* * * e}$ & $1.8(0.3)^{* * * e}$ & $1.1(0.2)^{* * * e}$ & $1.1(0.3)^{* * * e}$ & $-0.1(0.2)$ & $0.4(0.2)^{* e}$ & $0.5(0.6)$ \\
\hline Strongly disagree & $11.1(2.5)^{* * *}$ & $1.4(0.3)^{* * *}$ & $2.4(0.5)^{* * *}$ & $1.7(0.4)^{* * *}$ & $1.7(0.4)^{* * *}$ & $-0.3(0.4)$ & $1.0(0.3)^{* * *}$ & $2.2(0.9)^{*}$ \\
\hline \multicolumn{9}{|c|}{ Mother-adolescent relationship } \\
\hline Very good & Reference & Reference & Reference & Reference & Reference & Reference & Reference & Reference \\
\hline Relatively good & $5.3(0.9)^{* * *}$ & $0.4(0.2)$ & $1.0(0.2)^{* * *}$ & $0.9(0.1)^{* * *}$ & $1.0(0.2)^{* * *}$ & $0.1(0.2)$ & $0.6(0.1)^{* * *}$ & $0.7(0.4)$ \\
\hline General & $5.2(1.4)^{* * *}$ & $-0.1(0.2)$ & $1.1(0.3)^{* * *}$ & $0.6(0.2)^{* *}$ & $1.0(0.2)^{* * *}$ & $0.1(0.2)$ & $0.6(0.2)^{* * *}$ & $1.0(0.6)$ \\
\hline Relatively \& very bad & $12.0(3.2)^{* * *}$ & $0.7(0.5)$ & $2.4(0.7)^{* * *}$ & $1.4(0.5)^{* *}$ & $1.5(0.6)^{* *}$ & $1.0(0.5)$ & $1.3(0.4)^{* *}$ & $2.0(1.2)$ \\
\hline \multicolumn{9}{|c|}{ Father-adolescent relationship } \\
\hline Very good & Reference & Reference & Reference & Reference & Reference & Reference & Reference & Reference \\
\hline Relatively good & 2.6(1.1) & $0.0(0.2)$ & $0.5(0.2)$ & $0.3(0.2)$ & $0.4(0.2)$ & $0.0(0.3)$ & $0.5(0.3)$ & $1.3(0.3)^{* * *}$ \\
\hline General & $4.7(2.3)$ & $0.3(0.2)$ & $0.6(0.3)$ & $0.5(0.2)$ & $0.4(0.2)$ & $0.2(0.2)$ & $0.1(0.2)$ & $2.2(0.4)^{* * *}$ \\
\hline Relatively \& very bad & $4.2(2.2)$ & $0.1(0.3)$ & $0.8(0.5)$ & $0.4(0.3)$ & $0.5(0.4)$ & $0.2(0.1)$ & $-0.3(0.2)$ & $2.8(0.8)^{* * *}$ \\
\hline \multicolumn{9}{|l|}{ Parental marriage } \\
\hline Married-and-together & Reference & Reference & Reference & Reference & Reference & Reference & Reference & Reference \\
\hline Married-but-separated & $8.4(3.4)^{*}$ & $1.1(0.5)^{*}$ & $1.3(0.7)$ & $0.8(0.5)$ & $0.5(0.6)$ & $0.1(0.5)$ & $0.8(0.4)$ & $3.5(1.2)^{* *}$ \\
\hline Divorced & $0.9(2.4)$ & $0.3(0.3)$ & $0.0(0.5)$ & $0.0(0.3)$ & $-0.2(0.4)$ & $0.3(0.3)$ & $0.1(0.3)$ & $0.1(0.9)$ \\
\hline Widowed & $1.4(4.3)$ & $0.1(0.6)$ & $0.1(0.9)$ & $0.4(0.6)$ & $-0.3(0.8)$ & $0.5(0.6)$ & $-0.1(0.5)$ & $0.7(1.6)$ \\
\hline Remarried & $-0.0(2.3)$ & $0.2(0.4)$ & $-0.2(0.5)$ & $0.2(0.4)$ & $-0.3(0.5)$ & $0.2(0.4)$ & $-0.5(0.3)$ & $0.9(1.0)$ \\
\hline \multicolumn{9}{|l|}{ Family structure } \\
\hline Nuclear family & Reference & Reference & Reference & Reference & Reference & Reference & Reference & Reference \\
\hline Three-generation family & $-1.7(1.0)$ & $-0.2(0.1)$ & $-0.3(0.2)$ & $-0.2(0.1)$ & $-0.3(0.2)^{*}$ & $-0.0(0.1)$ & $-0.3(0.1)^{*}$ & $-0.4(0.4)$ \\
\hline
\end{tabular}


Table 4 Linear regression results for the associations between family factors and development of AIA/AIA symptoms ${ }^{\mathrm{a}, \mathrm{b}}$ (Continued)

\begin{tabular}{|c|c|c|c|c|c|c|c|c|}
\hline Single parent family & $0.8(2.6)$ & $-0.1(0.4)$ & $0.2(0.5)$ & $0.0(0.4)$ & $0.4(0.5)$ & $0.1(0.4)$ & $0.2(0.3)$ & $-0.1(1.0)$ \\
\hline Left-behind adolescents & $-0.3(2.3)$ & $-0.1(0.3)$ & $-0.5(0.5)$ & $-0.1(0.3)$ & $0.3(0.4)$ & $0.9(0.3)^{* *}$ & $-0.3(0.3)$ & $-0.7(0.8)$ \\
\hline Weekend parents & $1.9(2.4)$ & $0.5(0.3)$ & $0.7(0.5)$ & $0.1(0.4)$ & $-0.4(0.4)$ & $0.0(0.4)$ & $0.1(0.3)$ & $1.0(0.9)$ \\
\hline
\end{tabular}

${ }^{\mathrm{a}} \mathrm{AIA}=$ adolescent internet addiction.

${ }^{b}$ Linear regressions were used to model the relationship between family factors and AIA and between family factors and symptoms of 7 subscales. Total scores and subscale scores of DRM- 52 Scale were respectively taken as dependent variables. Adjusted $\mathrm{R}$ squares for these models were around 0.3 .

In these models, adolescent gender, age, grade, the type of school, monthly consumption expenditure, academic achievement levels and family social economic status were adjusted. Two variables including family In these models, adolescent gender, age.
structure and marital status were forced.

structure and marital status were forced.
${ }^{\mathrm{R}}$ Results are reported as Coefficient Estimate (SE).

e***indicated $p<0.001,{ }^{* * i n d i c a t e d} p<0.01,{ }^{*}$ indicated $p<0.05$ 
behavior adjustment greatly [28,29]. Another study of 55 Latino families revealed that mother-adolescent communication affected both adolescent behaviors and attitudes toward premarital sex and adolescents' perceptions of openness in the mother-adolescent relationship [30]. These studies were consistent with our results in showing the importance of improving mother-adolescent relationship in adjusting adolescent behaviors.

In our study, poor father-adolescent relationships were associated with the development of AIA, but were less significantly associated with AIA than maternal factors. This might suggest that, when compared with mothers, fathers in Chinese culture remain underrepresented in most child-related activities.

\section{Effects of marital status and family structure on AIA}

Our study showed that adolescents from three-generation families were less likely to develop symptoms of AIA than those from other kinds of family structures. This was consistent with previous studies $[17,19]$ and appeared to be due to supervision from both parents and grandparents.

Our study also showed that parental marital status of married-but-separated was marginally associated with AIA. One possible explanation is that adolescents might suffer from conflict or neglect as the separate status was maintained, and related emotional or behavioral problems might occur. Internet addiction might therefore develop due to the lack of parental supervision and adolescent emotional problems, similar to findings in previous studies [2,11,18,21,22,25].

Our study also showed that left-behind adolescents were prone to developing symptoms of AIA. Over the past twenty years, China has experienced rapid urbanization as more and more parents migrated from rural areas to cities or went abroad to enhance their careers or improve their economic condition. As a result, more adolescents were left behind. The prevalence of internet addiction among leftbehind adolescents was most probably due to lack of parental care and supervision [31,32].

\section{Limitations}

Firstly, there is no consensus on the diagnostic criteria for internet addiction. Although DRM-52 Scale was meant to absorb the essence of former instruments [11,12,33-35] and had relatively satisfactory psychometric properties, this scale might not be totally comprehensive and might need further refinement. The second limitation may be our reliance on data reported by adolescents themselves. Although anonymous questionnaires should have guaranteed confidentiality, a reporting bias is still possible. Thirdly, adolescents' perception of parent-adolescent relationship might not fully reflect the real situation [29]. Fourthly, we may miss some other family factors relating to AIA that were not included as variable candidates in our questionnaire.
Finally, our cross-sectional study raised the possibility of reverse causality, for example, that AIA may be a risk factor for worse mother-adolescent relationships (rather than the reverse).

\section{Conclusion}

To the best of our knowledge, this is the first detailed report on the relationship between adolescent internet use or addiction and patterns of parent-adolescent interaction. Our findings demonstrated that the quality of parent-adolescent (especially mother-adolescent) relationship/communication is closely associated with the development of AIA, but family SES or family structure is not. The present findings may be applied to family-based prevention and early intervention of AIA.

\section{Competing interests}

All authors have no competing interests to declare.

\section{Authors' contributions}

JX, CHY and XMS designed the study and supervised the data collection; JX drafted the manuscript; JX, LXS, XPL and JSZ undertook data collection; $\mathrm{HH}_{\text {, }}$ SRK, FY, LW and LNZ conducted the statistical analyses; JX, LXS, CHY, HH, $\mathrm{FXO}, \mathrm{JZ}$ and XMS assisted with the interpretation of results and revision for intellectual content. All authors read and approved the final manuscript.

\section{Acknowledgments}

We would like to thank Zeng-qiang WU and Zhen-zhen Ma (from Shanghai Academy of Educational Sciences) for assisting data acquisition. We thank Gail Fleischaker for professional language editing.

\section{Funding}

This study was supported by National Natural Science Foundation of China [30771814, 30901205, 81373016]; Shanghai Jiao Tong University School of Medicine [09XJ21016]; Shanghai Rising-Star Program [10QA1405700]; Shanghai Science and Technology Committee [124119a1400] 2010 SMC Chen-xin Plan C. These funding agencies had no further role in the study design, data collection, data analysis and interpretation, the writing of the report, and in the decision to submit the paper for publication.

\section{Author details}

'Xinhua Hospital, MOE-Shanghai Key Laboratory of Children's Environmental Health, Department of Child and Adolescent Healthcare, Shanghai Institute for Pediatric Research, Shanghai Jiao Tong University School of Medicine, Shanghai, China. ${ }^{2}$ Dalla Lana School of Public Health, University of Toronto, Toronto, Canada. ${ }^{3}$ Global Health Department, University of Michigan, Ann Arbor, Michigan, USA. ${ }^{4}$ Biostatistics Department, School of Public Health University of Michigan, Ann Arbor, Michigan, USA. ${ }^{5} \mathrm{Global}$ Health at University of Toronto's Faculty of Medicine, Toronto, Canada. ${ }^{6}$ Biostatistics Department, Shanghai Jiao Tong University School of Medicine, Shanghai, China.

Received: 14 January 2014 Accepted: 31 March 2014 Published: 15 April 2014

\section{References}

1. Moreno MA, Jelenchick L, Cox E, Young H, Christakis DA: Problematic internet use among US youth: a systematic review. Arch Pediatr Adolesc Med 2011, 165:797-805.

2. Durkee T, Kaess M, Carli V, Parzer P, Wasserman C, Floderus B, Apter A, Balazs J, Barzilay S, Bobes J, Brunner R, Corcoran P, Cosman D, Cotter P, Despalins R, Graber N, Guillemin F, Haring C, Kahn JP, Mandelli L, Marusic D, Mészáros G, Musa GJ, Postuvan V, Resch F, Saiz PA, Sisask M, Varnik A, Sarchiapone $M$, Hoven CW, et al: Prevalence of pathological Internet 
use among adolescents in Europe: demographic and social factors. Addiction 2012, 107:2210-2222.

3. Block JJ: Issues for DSM-V: Internet Addiction. Am J Psychiatry 2008 165:306-307.

4. Cao H, Sun Y, Wan Y, Hao J, Tao F: Problematic Internet use in Chinese adolescents and its relation to psychosomatic symptoms and life satisfaction. BMC Public Health 2011, 11:802.

5. Xu J, Shen LX, Yan $\mathrm{CH}$, Hu H, Yang F, Wang L, Kotha SR, Zhang LN, Liao XP, Zhang J, Ouyang FX, Zhang JS, Shen XM: Personal characteristics related to the risk of adolescent internet addiction: a survey in Shanghai, China. BMC Public Health 2012, 12:1106.

6. Christakis DA: Internet addiction: a 21st century epidemic? BMC Med 2010, 8:61

7. Stone R: Science in society. China reins in wilder impulses in treatment of 'Internet addiction. Science 2009, 324:1630-1631.

8. Thomée S, Härenstam A, Hagberg M: Computer use and stress, sleep disturbances, and symptoms of depression among young adults-a prospective cohort study. BMC Psychiatry 2012, 12:176.

9. Floros G, Siomos K: The relationship between optimal parenting, Internet addiction and motives for social networking in adolescence. Psychiatry Res 2013, 209:529-534

10. Wang H, Zhou X, Lu C, Wu J, Deng XQ, Hong L: Problematic Internet Use in high school students in Guangdong Province, China. PLOS ONE 2011, 6:e19660.

11. Weinstein A, Lejoyeux M: Internet addiction or excessive internet use. Am J Drug Alcohol Abuse 2010, 36:277-283.

12. Young KS: Psychology of computer use: XL. Addictive use of the internet: a case that breaks the stereotype. Psychol Rep 1996, 79:899-902.

13. Yen JY, Cheng-Fang Y, Chen CS, Chang YH, Yeh YC, Ko CH: The bidirectional interactions between addiction, behaviour approach and behaviour inhibition systems among adolescents in a prospective study. Psychiatry Res 2012, 200:588-592.

14. Wei HT, Chen MH, Huang PC, Bai YM: The association between online gaming, social phobia, and depression: an internet survey. BMC Psychiatry 2012, 12:92.

15. Yen JY, Ko CH, Yen CF, Chen SH, Chung WL, Chen CC: Psychiatric symptoms in adolescents with Internet addiction: Comparison with substance use. Psychiatry Clin Neurosci 2008, 62:9-16.

16. Yuan K, Qin W, Wang G, Zeng F, Zhao L, Yang X, Liu P, Liu J, Sun J, Von Deneen KM, Gong Q, Liu Y, Tian J: Microstructure Abnormalities in Adolescents with Internet Addiction Disorder. PLOS ONE 2011, 6:e20708.

17. Barrett $A E$, Turner RJ: Family structure and substance use problems in adolescence and early adulthood: examining explanations for the relationship. Addiction 2006, 101:109-120.

18. Yen JY, Yen CF, Chen CC, Chen SH, Ko CH: Family factors of Internet addiction and substance use experience in Taiwanese adolescents. Cyberpsychol Behav 2007, 10:323-329.

19. Giannakopoulos G, Mihas C, Dimitrakaki C, Tountas Y: Family correlates of adolescents' emotional/ behavioral problems: evidence from a Greek school-based sample. Acta Paediatr 2009, 98:1319-1323.

20. Schinke SP, Fang L, Cole KC: Computer-delivered, parent-involvement intervention to prevent substance use among adolescent girls. Prev Med 2009, 49:429-435.

21. Parker JS, Benson MJ: Parent-adolescent relations and adolescent functioning: self-esteem, substance abuse, and delinquency. Adolescence 2004, 39:519-530

22. Lin CH, Lin SL, Wu CP: The effects of parental monitoring and leisure boredom on adolescents' Internet addiction. Adolescence 2009, 44:993-1004

23. Park SK, Kim JY, Cho CB: Prevalence of Internet addiction and correlations with family factors among South Korean adolescents. Adolescence 2008, 43:895-909.

24. Shanghai Youth Federation, Hong Kong Federation of Youth Groups, Singapore People's Association Youth Movement: Adolescent Interne Addiction, Recognition and Intervention. 3rd edition. Shanghai: East China University of Science and Technology Press; 2006. Book in Chinese.

25. Dittus PJ, Jaccard J: Adolescents' perceptions of maternal disapproval of sex: relationship to sexual outcomes. J Adolesc Health 2000, 26:268-278.

26. Manaf RA, Shamsuddin K: Smoking among young urban Malaysian women and its risk factors. Asia Pac J Public Health 2008, 20:204-213.

27. Llorens N, Barrio G, Sánchez A, Suelves JM, ESTUDES Working Group: Effects of socialization and family factors on adolescent excessive drinking in Spain. Prev Sci 2011, 12:150-161.
28. Aroian K, Hough E, Templin TN, Kulwicki A, Ramaswamy V, Katz A: A mode of mother-child adjustment in Arab Muslim immigrants to the US. Soc Sci Med 2009, 69:1377-1386

29. Burk WJ, Laursen B: Mother and adolescent reports of associations between child behavior problems and mother-child relationship qualities: separating shared variance from individual variance. J Abnorm Child Psychol 2010, 38:657-667.

30. Romo LF, Lefkowitz ES, Sigman M, Au TK: A longitudinal study of maternal messages about dating and sexuality and their influence on Latino adolescents. J Adolesc Health 2002, 31:59-69.

31. Fan F, Su L, Gill MK, Birmaher B: Emotional and behavioral problems of Chinese left-behind children: a preliminary study. Soc Psychiatry Psychiatr Epidemiol 2009, 45:655-664.

32. Liu Z, Li X, Ge X: Left too early: the effects of age at separation from parents on Chinese rural children's symptoms of anxiety and depression. Am J Public Health 2009, 99:2049-2054.

33. Shapira NA, Lessig MC, Goldsmith TD, Szabo ST, Lazoritz M, Gold MS, Stein DJ: Problematic internet use: proposed classification and diagnostic criteria. Depress Anxiety 2003, 17:207-216.

34. Aboujaoude E: Problematic Internet use: an overview. World Psychiatry 2010, 9:85-90

35. Tao R, Huang X, Wang J, Zhang H, Zhang Y, Li M: Proposed diagnostic criteria for internet addiction. Addiction 2010, 105:556-564.

doi:10.1186/1471-244X-14-112

Cite this article as: Xu et al:: Parent-adolescent interaction and risk of adolescent internet addiction: a population-based study in Shanghai. BMC Psychiatry 2014 14:112

\section{Submit your next manuscript to BioMed Central and take full advantage of:}

- Convenient online submission

- Thorough peer review

- No space constraints or color figure charges

- Immediate publication on acceptance

- Inclusion in PubMed, CAS, Scopus and Google Scholar

- Research which is freely available for redistribution 